\title{
Imaginative Immersion, Regulation, and Doxastic Mediation
}

\author{
Alon Chasid, Bar-Ilan University
}

[forthcoming in Synthese]

\begin{abstract}
This paper puts forward an account of imaginative immersion. Elaborating on Kendall Walton's thesis that imagining aims at the fictional truth, it first argues that imaginings are inherently rule- or norm-governed: they are 'regulated' by that which is presented as fictionally true. It then shows that an imaginer can follow the rule or norm mandating her to imagine the propositions presented as fictional truths either by acquiring explicit beliefs about how the rule (norm) is to be followed, or directly, without acquiring such beliefs. It proceeds to argue that to the extent that an imaginer follows this rule (norm) without holding such beliefs, she is more immersed in her imaginings. The general idea is that immersion in an activity is a matter of following rules or norms that apply to that activity without explicitly thinking about how to follow them, that is, without 'doxastic mediation.' Lastly, the paper shows that this thesis can explain various features associated with imaginative immersion, such as the sort of attentiveness it involves, the emotional response it generates, and its relation to spoilers.
\end{abstract}

\section{Introduction}

We sometimes become lost in our imaginings. Whether we are imagining in response to reading or watching a work of fiction, or in the course of pretending, playing games of make-believe, 
daydreaming, etc., we often become engrossed in our imaginative activity. Although imaginative immersion is a familiar phenomenon, there is no consensus as to its cognitive structure. In $\S 2$, I survey and critique existing accounts of imaginative immersion, and identify what I take to be the core aspect of imaginative immersion. I argue that immersion is a matter of the way we follow the general rule or norm that governs imagining, namely, that imaginers are to imagine the propositions presented as fictionally true: to the extent that we follow this rule or norm without acquiring explicit beliefs about the specifics of how to follow it, we are more immersed in our imaginings.

To develop this idea, I first elucidate the sense in which imaginings are 'regulated,' that is, rule- or norm-governed. Drawing on Kendall Walton's thesis that imagining aims at the fictional truth as belief aims at truth (Walton 1990, 41), I argue that the imaginings in a given imaginative project are governed by that which is presented, at each stage of the project, as fictionally true. That is, in imagining, we ipso facto follow the rule (norm) that propositions that are presented as fictional truths are to be imagined (§3).

As in following rules in general, we can follow the rule or norm that regulates imagining, i.e., that propositions presented as fictional truths are to be imagined, either by acquiring explicit beliefs about the specifics of how to follow this rule (norm), or more directly, without such 'mediating' beliefs. To the extent that we imagine without explicitly thinking about which propositions we are to imagine, we are more immersed in imagining. Indeed, being immersed in imagining means that the rule in question becomes 'transparent' for us, in that we do not hold explicit beliefs about the details of how to follow it.

Since there are various ways in which propositions can be presented as fictionally true, the rule (norm) that such propositions are to be imagined, and the distinction between doxastically- 
mediated and non-doxastically-mediated compliance with this rule, apply in various ways. I discuss the various ways in which the rule can be followed in $\S 4$, showing how in every case, immersion arises from the absence of conscious, non-dispositional beliefs regarding the specifics of how the rule that regulates imagining is to be followed. Lastly, in $§ 5$, I show how the proposed account of imaginative immersion elucidates various characteristics of immersion, such as the 'attentiveness' and increased emotional engagement ascribed to an immersed imaginer. The paper ends with an explanation of the phenomenon of spoilers in terms of imaginative immersion.

\section{Imaginative Immersion: Background and Explication}

\subsection{Existing Accounts of Imaginative Immersion}

On the account of immersion proposed in Schellenberg (2013), imagining and belief exist on a continuum. Schellenberg argues that although 'pure' imaginings can be easily distinguished from beliefs, certain mental states — specifically, those that arise during imaginative immersioncannot be categorized as either imaginings or beliefs. The absence of a clear-cut distinction, she maintains, is similar to the absence of a clear-cut distinction between certain shades: whereas 'pure' yellow, e.g., can be readily distinguished from red, there are shades between yellow and red that cannot be categorized as either yellow or red. The lack of a clear distinction between imaginings and beliefs, Schellenberg claims, explains immersion. When we become immersed in imagining, we cease to be aware that we are imagining: we take the fictional world, temporarily, to be the real world (Schellenberg 2013, 507). We shift seamlessly from mental states that are 
'pure' imaginings to mental states that are more akin to belief, taking the content of our imaginings to be true, just as we take the content of our beliefs to be true (508-510).

Schellenberg's explanation of immersion is disputed by Liao and Doggett (2014), who adduce evidence to the effect that immersed imaginers are aware of real-world facts, and do not take the imagined content to be true. A subject who is immersed in, e.g., playing with playdough, does not try to bite a playdough cookie; an actor who is immersed in imagining himself to be a fictional character is fully aware of the camera's presence. Chasid (2017) challenges Schellenberg's view by showing that in addition to imagining, imaginers also posit an imaginary world at which their imaginings are directed. Since imaginings are assessed for truth in the posited world, whereas beliefs are assessed for truth in the real world, the difference between imaginings and beliefs is categorical, not gradational.

In light of these critiques, we can endorse the claim that immersed imaginers do not believe the content of their imaginings. Yet there seems to be a sense in which immersion increases the similarity between imaginings and beliefs (a claim that may be compatible with some of Schellenberg's observations), though imaginings and beliefs are categorically different. I will explain this similarity by drawing on Kendall Walton's thesis that imagining aims at fictional truth just as belief aims at truth (Walton 1990, 41). I will argue that the more one is immersed in imagining, the more imaginings function like beliefs with respect to their regulation by the propositions presented as 'truths' (in the case of beliefs, real-world truths, in the case of imaginings, fictional truths).

Other accounts of immersion explain it in terms of attentiveness. Explaining immersion in terms of attentiveness is appealing, since in some contexts, e.g., that of conversation, being 'immersed' seems to entail no more than profound attentiveness. Liao (unpublished) argues that 
the difference between immersed and non-immersed imaginers lies in "the information that they attend to. Immersed pretenders and actors attend to the fictional content of make-believe. ... But non-immersed pretenders and actors attend to make-believe itself" (7). Likewise, someone who 'loses' herself in reading or watching a work of fiction attends to the "happenings of the story world" rather than "the writing style, the plot structure, and other features about the book itself" (7). Kampa (2018) similarly invokes the notion of attentiveness to explain how actors, for instance, by paying attention to the content of the "Possible World Box" (692), become immersed in imagining themselves to be fictional characters, and thus engage in imaginative transportation.

The problem with attention-based accounts of immersion is that it is unclear how attentiveness can differentiate between immersed and non-immersed imaginers. Given that we seek to explain the difference between immersed and non-immersed imaginers, not the difference between an imaginer and a non-imaginer (e.g., between a reader who imagines a story she reads, and one who merely reads it to proofread it), what does it mean to say that an immersed imaginer 'attends' to what she imagines more deeply than a non-immersed imaginer does? Presumably, subjects can imagine the same fictional content, but be immersed in their respective imaginings to different degrees. ${ }^{1}$ If so, then without further qualification, attentiveness does not distinguish immersed imaginers from non- (or less-) immersed imaginers.

\footnotetext{
${ }^{1}$ In arguing against Schellenberg, Liao and Doggett (2014, 266-267) adduce a case where the difference between non-immersed and immersed pretenders is clearly categorical: a mother playing 'cops and robbers' with her son first believes 'I'm a mother who's pretending to be a cop,' but upon becoming immersed in the game, imagines 'I'm a cop.' But this case, where there
} 
Granted, there is a sense in which an immersed imaginer feels 'drawn' by the fictional content, and 'attends' to it — without losing track of reality—-more intensely than a non-immersed imaginer does. But this sense of attentiveness is not a matter of the imagined content. Rather, it is a matter of the way in which imaginers follow the general rule or norm that governs imagining. I contend that an imaginer is more immersed in imagining to the extent that she follows the rule or norm that generally governs imagining (namely, that we are to imagine that which is presented as fictionally true; see below) without the mediation of explicit beliefs about the details of how it is to be followed. The idea is that in imagining, as in certain other contexts, being immersed (absorbed, engrossed) is a matter of how a subject engages in a rule-governed activity. Another account of imaginative immersion associates it with emotional engagement with fictional content. Langland-Hassan, for instance, takes immersion in fiction to be "nothing over and above being deeply emotionally engaged by [the fictional content]" (Langland-Hassan 2020, 186). He then argues - in line with his overall theory of imagination, which reduces imaginings to folk-psychological states - that immersion (i.e., deep emotional engagement with fictional content) can be explained by adducing the imaginer's beliefs and desires regarding what happens in the work in question (ch. 11).

is a shift from believing to imagining, is irrelevant to providing an account of immersion, where the crucial distinction is that between an immersed imaginer and a non- (or less-) immersed imaginer. With regard to this distinction, the relevant shift is a shift from one imagining to another imagining, both of which have the content 'I'm a cop.' 
Setting aside certain difficulties in Langland-Hassan's reductive theory, ${ }^{2}$ the problem with his account of immersion is that imaginative immersion need not be accompanied by emotional engagement. We can be intrigued by a novel's plot and become immersed in it, without being moved by the fictional content, simply because no particular emotional response is relevant to that content. Indeed, empirical studies of imaginative immersion have found it to be associated, to varying extents, not only with emotional responses, but also, e.g., with an experience of 'flow,' a sense of 'being present' in the fictional world, vividness of mental imagery, etc. (see, e.g., Green and Donahue 2009; Iachini et al. 2019). To the extent that emotions are aroused by the imagined content, immersion may involve deep emotional engagement (see $§ 5$ below). But since immersion need not involve emotional responses, it cannot be identified with them. To

${ }^{2}$ Briefly, there are two respects in which Langland-Hassan's thesis that imaginings are beliefs (judgments, desires, etc.) may be problematic. First, we sometimes believe that it is fictionally true that $p$, but imagine that not- $p$, hence imaginings cannot be defined as beliefs about a given fictional scenario. For instance, we may know (say, from a spoiler) the identity of the murderer in a certain murder mystery, but we can nonetheless imagine, in reading the mystery's first chapters, that the murderer is someone else, as per the work's initial intimations. In such cases, what we imagine differs from what we believe about the fictional content. The same is true vis-àvis other folk-psychological attitudes to the fictional content $p$ : we can have those attitudes while imagining not- $p$. Secondly, consider spontaneous imaginings. Since beliefs arise for a reason or in response to evidence, whereas spontaneous imaginings are extemporaneous, spontaneous imaginings cannot be identical to beliefs about the fictional scenarios. 
account for immersion, the focus should be on how we imagine, not how we react to our imaginings.

The same problem afflicts accounts that try to characterize immersion, or explain it, in terms of how imaginings motivate us to act (see Sinhababu 2016, §4). Immersion cannot be characterized or explained in terms of how imaginings motivate the imaginer to act (e.g., in pretending), because one can be immersed in imagining (e.g., in daydreaming, engaging with works of fiction, etc.) without being motivated to act, or acting. In general, the 'outputs' of imagining - emotions, motivations, etc.-can be affected by state of immersion, but as such, can neither be identified with immersion nor explain it.

\subsection{The Core Aspect of Immersion}

My account of immersion indeed focuses on how imaginings arise. It invokes the fact that being immersed in an activity sometimes connotes 'direct' compliance with that activity's rules or norms. In such cases, one follows those rules or norms without explicitly thinking about how to do so. For instance, when immersed in a culture, language, or yoga practice, one's activity is governed directly by the applicable rules: one follows the rules without acquiring (in real time) explicit beliefs about how they are to be followed in the specific situation at hand. Consider linguistic activity. Learning a language usually involves the acquisition of beliefs about how sentences in that language are structured, e.g., beliefs about the language's default word order, i.e., the order in which subjects, verbs, direct and indirect objects are ordinarily arranged. Until we master the language, in composing a sentence, we must explicitly think about the grammatical roles played by each of the words we intend to use. Following the language's 
syntactical rules requires us, with respect to every sentence we formulate, to acquire explicit beliefs about how the rules apply to the words we use.

At a certain stage, however, we become immersed in the language, and need not acquire such beliefs. We build up sentences 'automatically,' without explicitly thinking about each word and its grammatical role. Moreover, once our activity is governed by the rules directly, i.e., without explicit doxastic mediation, we cannot articulate how the rules apply to the sentences we are uttering without compromising our immersion: specifying how the rules of grammar apply to the particular sentences we are uttering reduces our degree of immersion.

This is true not only of immersion in linguistic activity, but also of immersion in other regulated activities. My main thesis is that it is likewise the core aspect of imaginative immersion. Someone immersed in imagining hardly holds explicit beliefs about the specifics of how to apply the rule or norm that 'regulates' imaginative activity. Granted, there are differences between immersion in cultures or languages, and immersion in pretense, works of fiction, daydreams, and other sorts of imaginative projects; imaginative immersion ensues from the way imaginings are regulated. As I will explain in $\S 3$, imaginings are inherently regulated by that which is presented as fictionally true in the pertinent imaginative project. (The various ways in which an imaginer can follow the rule that such propositions are to be imagined, whether via doxastic mediation or directly, and accordingly, the various ways in which imaginative immersion can arise, will be elucidated in $\S 4$.)

Two preliminary comments are in order. First, my account of imaginative immersion is neutral with respect to the metaphysics of rule-following. Famously, Kripkean skeptics maintain that rule-following cannot be explained in terms of intentions or other mental representations (chiefly because such an explanation presupposes the notion of rule-following), nor can it be 
explained in terms of the subject's dispositions. Rather, rule-following is sui generis or has a primitive component (see, e.g., Boghossian 2005; 2008; Ginsborg 2011; Schlosser 2011). Others downplay Kripkean skepticism and develop accounts of rule-following that do invoke intentional or dispositional elements (e.g., Pettit 1990; Schlosser 2011; Horst 2019; for an overview, see Glüer and Wikforss 2020). My account of immersion does not presuppose any of these accounts. Specifically, the distinction between following a rule by thinking about the details of how to follow it in a particular situation (e.g., in following grammatical rules, by acquiring explicit beliefs about which term in a sentence is the subject, which is the verb, etc.), and following a rule without explicitly thinking about these specifics, is pre-theoretical. It is, indeed, a psychological fact that we can follow a rule either by explicitly pondering the details of its application in a particular case, or without pondering those details. The crucial point for my argument is that this general distinction applies to imagining: the rule or norm that regulates imagining (see §3) can be followed by way of explicit doxastic mediation, or without explicit doxastic mediation (§4).

The second comment pertains to my use of the term 'explicit belief.' Explicit beliefs should be distinguished not only from sub-personal representations (Lyons 2016), but also from three types of beliefs discussed in the literature. First, explicit beliefs differ from non-occurrent beliefs, namely, belief-representations that are stored in memory without being currently retrieved (see, e.g., Audi 1994; Schwitzgebel 2019, §2.1). Second, explicit beliefs differ from states that, though not stored in memory, are "swiftly derivable" from what one believes to be true (Schwitzgebel 2019, §2.2.1; Audi 1994 deems such beliefs mere "dispositions to believe”). Third, explicit beliefs are conscious, and hence differ from representational states deemed to be unconscious beliefs (see, e.g., Mandelbaum 2016 and Frankish 2016 on implicit bias; Lyons 2016 on epistemic justification). 
My invocation of 'explicit' beliefs is intended to exclude the aforementioned types of states. Explicit beliefs are invoked vis-à-vis situations where a rule or norm is followed by the imaginer's consciously representing, in an occurrent belief, the details relevant to its application. My claim is that immersion in an activity depends on the extent to which we acquire such explicit beliefs: to the extent that we follow a rule without the mediation of explicit beliefs, we are more immersed in our activity. Specifically, in imagining, to the extent that we follow the rule or norm that governs imagining without acquiring explicit beliefs, we are more immersed in our imaginings.

Before defending this claim, I must first unpack the thesis that imagining is rule- or normgoverned.

\section{The Regulation of Imaginings}

It is often claimed that imaginings are generally unconstrained, that we are ordinarily free to choose what to imagine. Though there do seem to be a few cases where it is difficult or impossible to imagine certain propositions-e.g., overt logical contradictions (Kind 2013,151) and morally- or aesthetically-deviant propositions (as per the puzzle of imaginative resistance; see Tuna 2020) - it is hard to deny that imaginings are largely unconstrained. This lack of constraint comes to the fore when imaginings are compared to beliefs vis-à-vis their respective commitments to truth. Beliefs are committed to truth, imaginings are not. Similarities between imaginings and beliefs exist at the level of 'output': imaginings can generate emotional responses, conative states, and other kinds of states that are identical or similar to those generated by beliefs with the same content. But imaginings and beliefs differ vis-à-vis truth- 
commitment: imaginings, unlike beliefs, are not responsive to evidence, their content need not be consistent with the content of the imaginer's beliefs, etc.

There is, however, a different sense in which imaginings are constrained or 'regulated.' This sense is explained in Walton (1990, 39ff). Accepting that imaginings are not truth-committed, Walton argues that every imaginative project involves propositions that are to be imagined: a subject who does not imagine these 'to-be-imagined' propositions is either not engaged with the project, or is imagining "improperly" (39). At first sight, Walton's claim can be interpreted superficially: the mandate to imagine certain propositions is expressed through instructions or intentions to imagine. For instance, if we decide or agree to imagine that we are "traveling to Saturn in a rocket" (39), then if we do not imagine this proposition (and related ones), we violate our decision or agreement. Likewise, if a work of fiction instructs us to imagine, say, that the protagonist lives in London Ontario, and in reading that work, we imagine that the protagonist lives in London England, our imaginings are 'improper,' since we are not imagining what we were instructed to imagine.

Violation of instructions or agreements to imagine, however, does not establish that imaginings are inherently subject to regulation. If imaginings are constrained only by external guidance, then imaginative projects, in themselves, are not inherently rule-governed. Walton's thesis goes beyond this simple claim: its import is that imaginings are internally regulated. For one thing, Walton asserts that spontaneous imaginings are also regulated (1990,44). For another, Walton seems to maintain that even when imaginings are prompted by instructions or intentions, and in that sense externally regulated, this regulation is contingent, and had those imaginings arisen without any prompting by instructions or intentions, they would still have been subject to regulation of a different sort. 
To understand Walton's point, consider one of his best-known examples, a game of makebelieve in which the players take tree-stumps in a forest to be bears (1990, 37ff.). In this game, tree-stumps serve as "props," as "generators of fictional truths" (37). The players accept that if it is true that there is a tree-stump at a certain spot, it is fictionally true that there is a bear at that spot. This stipulation also guides the players' imaginings: if they believe that there is a treestump at a certain spot, they imagine that there is a bear at that spot. Walton emphasizes that players do not necessarily imagine every fictional truth (specifically, every proposition that follows from the stumps-are-bears stipulation); there may, e.g., be tree-stumps they are unaware of. Nor does it follow that whatever players imagine is fictionally true: they can, e.g., mistake a moss-covered boulder for a tree-stump, and thus imagine the fictional falsehood that there is a bear where the boulder is.

Walton's example demonstrates that imaginative projects have two distinct elements: (a) stipulated fictional truths (or a 'fictional world,' i.e., a set of fictional truths; see Walton 1990, 66-67), and (b) imaginings (the content of an imagining is either a fictional truth or a fictional falsehood). The regulation of imagining, Walton argues, follows, not from these elements in themselves, but from their relation: fictional truths are propositions that are to be imagined. This relation - the relation between imaginings and fictional truths - is the same as the relation between beliefs and truths: "imagining aims at the fictional [truth] as belief aims at the true. What is true is to be believed; what is fictional is to be imagined" (Walton 1990, 41).

On Walton's view, then, when we engage in an imaginative activity, our imaginings are constrained by the pertinent fictional truths. Qua imaginers, we act, vis-à-vis fictional truths, just as we act, qua believers, vis-à-vis truth simpliciter. Granted, in believing, we cannot alter or- to the extent that we act rationally—disregard truths simpliciter, whereas in imagining, we are free 
to alter or disregard fictional truths, either by ending the imaginative project, or by engaging in a different imaginative project (i.e., a project with different fictional truths). In this respect, our imaginative activity indeed differs from our doxastic activity. But while we are engaged in a specific imaginative project, our imaginings are regulated by the fictional truths of that project, just as beliefs are regulated by truth simpliciter.

It is important to distinguish between the rule or norm that regulates imagining in general, and stipulations that determine which propositions are fictionally true. The stumps-are-bears stipulation, for instance, can be seen as a principle that determines fictional truths (see Walton 1990, §I.4 regarding "principles of generation”; see also $§ 4$ below). By grasping this stipulation, participants in the game, as well as non-participants, can discover which propositions are considered fictional truths of the game. But only participants are mandated to imagine these fictional truths: qua imaginers, they are subject to imaginative regulation, i.e., they must follow the general rule or norm mandating that fictional truths are to be imagined. Imaginative regulation obviously operates via stipulations that determine fictional truths, but should not be identified with these stipulations. Given that we are mandated to imagine fictional truths, they must somehow be set down. But imaginative regulation should not be identified with stipulations or any other mechanism for setting down which propositions are fictionally true.

Let us examine how imagining 'aims at the fictional truth' in the stumps-are-bears game. The stipulation that tree-stumps are fictional bears, in itself, does not mandate that the players imagine anything: it only entails that certain fictional truths obtain. Upon seeing a tree-stump, the players are induced to imagine a bear, since they are following the rule or norm that governs imaginings in general, namely, that imaginers are to imagine that which is fictionally true. Similarly, when we engage with a work of fiction, we are induced to imagine the work's content 
because the work presents that content as true. That is, in reading or watching the work, we track the propositions it presents as truths, take them to be the fictional truths of our imaginative project, and, in line with the rule or norm governing imaginings in general, we imagine those propositions. $^{3}$

The import of Walton's claim that imagining aims at the fictional truth just as belief aims at truth is that, to a great extent, the practices we adopt regarding what to imagine parallel our epistemic practices. Consider sensitivity to evidence. Usually, evidence to the effect that a certain proposition is true induces us to believe that proposition; absent evidence or beliefs to the contrary, we wind up believing that which we have evidence for. Of course, we sometimes act irrationally (e.g., self-deception). But we hardly seek, systematically and deliberately, to ignore evidence: being truth-directed, our beliefs are inherently responsive to evidence. On Walton's view, the same is true of imagining vis-à-vis fictional truth. If an imaginer has evidence to the effect that a certain proposition is true, she is induced to imagine it; absent evidence to the contrary, she winds up imagining it.

Here, however, imagining's similarity to belief breaks down, hence Walton's claim seems to be incorrect. We can have clear-cut evidence that certain propositions are fictional falsehoods, yet deliberately imagine them — without violating any rule or norm. Moreover, it seems that, in such cases, we are mandated to imagine fictional falsehoods. For instance, a novel's early chapters might present the protagonist as benevolent, a plan as successful, or a building as about

\footnotetext{
${ }^{3}$ Walton's idea also applies to spontaneous imaginings: spontaneously imagining a proposition presupposes that the proposition is also (spontaneously) set down as fictionally true (1990, 4445).
} 
to explode, whereas the last chapters reveal that the protagonist was malevolent, the plan was a failure, and the building was not about to explode. In such cases, readers of the early chapters are mandated to imagine fictional falsehoods. This is so even when novels are read a second time. In rereading the early chapters, i.e., while knowing the novel's fictional truths, readers are to set aside their knowledge of those fictional truths, and imagine propositions they know to be fictionally false.

Imaginers are similarly mandated to deliberately imagine fictional falsehoods in other contexts too. A participant in the stumps-are-bears game might plan to imagine (for fun, learning, etc.) that she is unaware of a bear, surprised by a bear, etc. Knowing that there is a stump behind her, and therefore that it is fictionally true that there is a bear behind her, she has no difficulty in imagining the fictional falsehood that there is no bear there, as per her planned 'simulation.' It seems that, in general, imaginings are structured so as to allow us to 'simulate' erroneous perspectives, that is, to imagine fictional falsehoods. Parallel cases of belief-i.e., cases where we straightforwardly believe, upon intention or instruction, what we know to be false — are highly implausible. That belief and imagining differ so significantly vis-à-vis their sensitivity to evidence seems to undermine Walton's claim that imagining aims at the fictional truth just as belief aims at truth.

I will not propose a full answer to this problem here, since my focus is the relation between the regulation of imagining and imaginative immersion. Elsewhere I have proposed revising Walton's thesis so that imagining is regulated, not by fictional truth, but by that which is presented, at each stage of the imaginative project, as fictionally true. This claim is explained by the fact that, in imagining, we are ipso facto posited to play the role of fictional believers (see Chasid 2019; forthcoming-a). That is, imagining entails acting as though, in the fictional world, 
our perspective is doxastic; it thus follows that imaginings are sensitive, not to fictional truth, but to that which is presented (at each stage of the project) as fictionally true. Hence if a work initially depicts a character as benevolent, we are mandated to imagine that the character is benevolent even if we are rereading the book and know it to be fictionally false that she is benevolent. This mandate ensues from the fact that the character is, initially, presented as being benevolent. Adopting the perspective of fictional believers, we track the 'evidence' provided at each stage, and imagine the character as benevolent. Similarly, in the stumps-are-bears game, if a participant plans to imagine the fictional falsehood that there is no bear behind her, she can set aside her knowledge of the tree-stump behind her, imagining, say, that, being preoccupied with something else, she is unaware of the bear behind her.

A comprehensive defense of the 'fictional doxastic perspective' thesis cannot be provided here. For the sake of argument, instead of saying that imaginings are regulated by fictional truths (as Walton argues), we can say that they are regulated by that which is presented as fictionally true at each stage, or - to abbreviate — by the apparent fictional truths. Note that this revision of Walton's thesis is a minor element of the proposed account of immersion, which can be readily adapted to fit views that uphold Walton's original thesis, and argue that normally, our practices vis-à-vis imagining and fictional truths are the same as our epistemic practices.

Given that the general rule or norm that regulates imagining is that imaginers are to imagine the propositions presented, at each stage of a project, as fictional truths, the core aspect of immersion pertains to how this general rule or norm is followed, a question discussed in the next section.

\section{Imaginative Immersion and Doxastic Mediation}




\subsection{Imagining without (Explicit) Doxastic Mediation}

There are various ways in which propositions can be presented as fictional truths, and hence various ways in which an imaginer can follow the general rule or norm that such propositions are to be imagined. What is crucial to immersion is the extent to which following this general rule or norm involves explicit beliefs about the specifics of how it is to be followed, i.e., beliefs about which propositions are presented as fictional truths. I will defend the thesis that the less one imagines by virtue of acquiring such beliefs, the more immersed in imagining one is.

Note that I am not speaking of beliefs whose content 'replicates' the content of real-world beliefs. It is widely accepted that imaginings are routinely informed by the imaginer's beliefs. ${ }^{4}$ For instance, in imagining Paris at night, a devastating earthquake, or a wombat, our imaginings generally replicate what we believe about Paris, earthquakes, and wombats. In defending the thesis that the fewer the imaginer's (explicit) mediating beliefs, the greater her immersion, I am not speaking of beliefs that play this sort of 'background' role. Rather, I am speaking of beliefs about the fictional world (i.e., the 'world' of a game, pretense, work of fiction, etc.).

Note also that, although having beliefs about the fictional world entails that the subject possesses the concept of fiction, it does not entail that the subject understands this concept at the metaphysical or philosophical level. ${ }^{5}$ What is crucial for the proposed account is that imaginers

\footnotetext{
${ }^{4}$ See, e.g., Walton (1990) ch. 4; Currie and Ravenscroft (2002), 12ff; Nichols (2006), §3.5. And see $\$ 4.2$ below.

${ }^{5}$ A similar claim is made by Langland-Hassan (2020, ch. 7) regarding the concept of pretense.
} 
are capable of distinguishing between reality and fiction, or between what obtains in reality and what obtains in the world of a game, pretense, fictional work, etc. Given that an imaginer is capable of making this distinction, she can likewise have explicit beliefs about the fictional. Indeed, it is widely accepted by psychologists and philosophers that not only adults and teens, but even children as young as two years old, can distinguish between reality and fiction (see, e.g., Harris and Kavanagh 1993; Leslie 1994; Currie 1998; Harris 2000; Nichols and Stich 2003; Nichols 2006; Langland-Hassan 2020). Moreover, it has been shown that young children can explicitly distinguish not only between reality and fiction, but also between different fictional worlds (Skolnick and Bloom 2006). It follows that young children, in particular, may also have explicit beliefs about the fictional world of their game of make-believe, pretense, etc., and hence, according to the proposed account, they can be immersed in their imaginings to varying degrees. ${ }^{6}$

\footnotetext{
${ }^{6}$ Since young children can be immersed in imagining to varying degrees, it is important to acknowledge their ability to hold explicit beliefs about the fictional world, as per my claim that the more an imaginer holds such beliefs, the less immersed she is. For one thing, when asked about the fictional world (e.g., the world of the game of make-believe they just played), young children respond in a manner demonstrating that they can hold such explicit beliefs. For another, when invited to play a new game, or when a new stipulation or prop is introduced during a game, they can acquire such beliefs (e.g., 'this box is an oven'; 'this coin is a pie'; etc.). To the extent that young children engage in imagining (and not in falsely believing fictional content), they can distinguish between reality and fiction, and hold beliefs, explicit or non-explicit, about the fiction; they can thus be immersed to varying degrees.
} 
Let us see how the thesis that the less we imagine by virtue of acquiring explicit beliefs, the more immersed in imagining we are, applies to the stumps-are-bears game. (For convenience, 'beliefs' will hereafter refer to explicit beliefs, unless otherwise stated). ${ }^{7}$ Consider a scenario in which a player: (1) visually experiences a tree-stump at a certain spot, and accordingly, (2) believes that it is fictionally true that there is a bear there, and therefore, (3) imagines that there is a bear there. ${ }^{8}$ On this scenario, stage (2) mediates between stages (1) and (3): the player imagines a bear by virtue of believing that it is (apparently) fictionally true, in the game she is playing, that there is a bear at that spot.

\footnotetext{
${ }^{7}$ As explained in $\$ 2.2$, my account is compatible with the claim that even fully-immersed imaginers can have non-occurrent, dispositional, or unconscious beliefs about the fictional world. The crucial point is that immersed imaginers do not explicitly think about which propositions are to be imagined, and hence imagine the propositions without explicit doxastic mediation. ${ }^{8}$ It might also be the case that stage (2) does not ensue directly from stage (1), but from the perceptual belief that there is a tree-stump at that spot, which follows from (1). The present paper does not focus on this sort of doxastic mediation, viz., doxastic mediation of perceptual experience; my account of immersion is compatible both with accounts that uphold it, and accounts on which imaginings ensue directly from visual experiences, without the mediation of perceptual beliefs. Likewise, my account is compatible with doxastic theories of perception, on which the visual experience at stage (1) is nothing more than the perceptual belief that there is a tree-stump at a certain spot. The key question vis-à-vis immersion is whether beliefs about the apparent fictional truths are generated by a perceptual experience.
} 
Compare this scenario to a different scenario, in which the player reaches stage (3) without going through stage (2): she visually experiences a tree-stump at a certain spot, and therefore imagines that there is a bear there. The player's imagining that a bear is there ensues directly from her visual experience of the tree-stump. Of course, in both scenarios, the player is generally aware that she is playing a game of make-believe in which tree-stumps are stipulated to be fictional bears. But only in the second scenario is it the case that she does not acquire beliefs about the specifics of how to apply the general rule or norm governing imagining. She imagines that there is a bear at that spot immediately upon seeing a tree-stump, without the mediation of the belief that it is fictionally true, by virtue of the stumps-are-bears stipulation, that there is a bear there. Since, on this scenario, the player's imaginative activity is not mediated by beliefs about the specific to-be-imagined propositions, she is deemed more immersed in her imaginative project than she is on the first scenario.

The distinction between imagining that involves acquiring beliefs, and 'direct' imagining, applies not only to imaginings that arise in response to perceptual experience, but also to other imaginings. In the stumps-are-bears game, for instance, suppose the players imagine carrying out specific (fictional) actions. A player might imagine that she is searching for a bear behind a clump of bushes. She can do so either indirectly, by first acquiring the belief 'it is fictionally true that I am searching for a bear,' or directly, without holding this belief. In the latter case, she is deemed more immersed in imagining than in the former, since her compliance with the general rule that she is to imagine that which is presented as fictionally true involves less doxastic mediation.

As explained in $\S 2.2$, the distinction between following a rule or norm by way of doxastic mediation and following it without doxastic mediation applies not only to imagining, but also to 
other regulated activities, e.g., linguistic activities, cultural activities, etc. To the extent that we do not acquire explicit beliefs about the details of how to follow grammatical rules or cultural norms, we are more immersed in the activity, since we follow the relevant rules or norms without consciously invoking the specifics of how they apply in each case (e.g., we can form a sentence without explicitly thinking that a certain phrase, being a noun phrase, can serve as the subject, and that another phrase can serve as the predicate, etc.) An immersed imaginer likewise has fewer (or no) explicit real-time beliefs as to how her imaginings are to unfold. She imagines without the involvement of such beliefs, and does not need to consciously 'step outside' her imaginings, so to speak, to ensure their compliance with that which has been presented as fictionally true.

\subsection{Varieties of Doxastically-(Un)Mediated Imaginings}

In the example discussed in $\S 4.1$, the imaginer's degree of immersion was a function of a single variable, namely, whether her imaginings ensued directly from visual experience, or indirectly, via beliefs regarding what her visual experience implied about the pertinent fictional truths. In addition to visually experiencing props (e.g., tree-stumps in the 'stumps-are-bears' game), there are other ways in which propositions can be presented as fictional truths, i.e., as 'to-be-imagined' propositions. With respect to each of these ways, such propositions can be imagined either via doxastic mediation, or without doxastic mediation. Hence an imaginer's degree of immersion depends on several variables. Indeed, given that immersion is gradational and not binary, the degree to which an imaginer is immersed reflects the overall number of mediating beliefs she acquires. I will now elucidate this point further, explaining how with respect to each of the 
various ways in which propositions can be presented as fictionally true, we can imagine by acquiring explicit beliefs about these 'to-be-imagined' propositions, or without acquiring such beliefs. Again, the argument applies to each such way: to the extent that an imaginer 'exits' her stream of imaginings to ascertain whether a proposition is presented as fictionally true, she is less immersed in her imaginings.

Let us first consider guided imaginative projects: projects that are prompted by an intention, or arise in response to instructions, etc. Consider the case of engaging with a work of fiction. Aware that we are reading fiction, we imagine the work's (apparent) fictional truths. We do so by apprehending, at each stage in the unfolding of the narrative, the propositions that the work describes as truths. ${ }^{9}$ We take these propositions to be the fictional truths - the to-be-imagined propositions - and imagine them. In other words, we follow the general rule or norm that these 'truths' are to be imagined. But do we follow it by acquiring beliefs about how to follow it?

Consider two scenarios. On one scenario, we: (1) apprehend the propositions that the work presents as truths, (2) believe that these propositions are presented as fictional truths (and hence are 'to be-imagined'), and (3) imagine these propositions. On this scenario, our imaginative activity is regulated by the apparent fictional truths indirectly, via mediating beliefs (stage 2). On the second scenario, no mediating beliefs arise. We: (1) apprehend the propositions that the work presents as truths, and (2) imagine them. We do not acquire beliefs about which propositions we

\footnotetext{
${ }^{9}$ Note that the way in which a work of fiction describes something as true does not depend on any specific theory of fiction or imagination: we discover what a work of fiction describes as or assumes to be true just as we discover what works of nonfiction (e.g., histories, biographies, newspaper articles, etc.) describe as or assume to be true. See Chasid (forthcoming-b).
} 
are supposed to imagine. Rather, we respond to the work directly by imagining the propositions it presents as truths. Here, we are more immersed in imagining than we were on the first scenario. Although on both scenarios we are aware that we are engaging with fiction, in the case of the first scenario, conscious, occurrent beliefs about the apparent fictional truths 'disrupt' our imaginative activity: in addition to being attentive to the fictional content by simply imagining it, we also attend to that content by holding explicit beliefs about its having been presented by the work as fictionally true, diminishing our immersion.

When engaging with fiction, we also 'inflate' the fictional world beyond what is overtly described by the work. The ability to imagine implied fictional truths by imagining explicit ones ensues from a belief-like feature of imagining in general. There is broad agreement that imagining mirrors the inferential patterns of belief. ${ }^{10}$ Applying these inferential patterns in imaginative projects involves not only imaginings (e.g., imagining that $p$, and imagining that if $p$ then $q$, can lead to imagining that $q$ ), but also beliefs, which can lead to replication, in our imaginative project, of the content of our beliefs about the real world. For instance, in imagining that the protagonist is human, we are ordinarily (i.e., absent defeating conditions) led to imagine that she has salient human properties; in imagining that clouds are blocking the sun, we are ordinarily led to imagine that it's getting darker outside, as per our belief that it gets darker outside when the sun is blocked; etc. Our beliefs about imagined objects or events inform our imaginings through the patterns of inference that apply to beliefs.

${ }^{10}$ See, e.g., Walton (1990) ch. 4; Currie and Ravenscroft (2002), 12ff; Nichols and Stich (2003), §2.4; Nichols (2006), §3.5; Weinberg and Meskin (2006), 180-181; Van Leeuwen (2013); Stock (2017), §6.2. 
Vis-à-vis immersion, the relevant question is whether these patterns apply directly, or via explicit beliefs about the implied fictional truths. In engaging with a work of fiction, if we have to consciously ponder whether it implies that a certain proposition is fictionally true or fictionally false, or whether the fictional world is indeterminate in this respect, our degree of immersion is reduced. Such a need to actively draw inferences about the fictional world might arise if we do not immediately grasp how the pertinent fictional world is structured, which implied 'facts' are essential to the plot, where the work is leading us. In reading a description of, e.g., two old friends strolling through a park as the sun is setting, we imagine the explicitly-described content, and may find it natural to inflate that content and imagine that the protagonists have certain thoughts, memories, and emotions, that twilight shadows are being cast on the path through the park, etc. But why is only this sort of inflation of the fictional world natural? Why not proceed to further imagine that the protagonists like ice-cream (who doesn't?), or that nuclear fusion is occurring in the sun? After all, these propositions can also follow by the said patterns of inference.

How we discover the implied to-be-imagined propositions is indeed a key question. Philosophers have suggested that this might require familiarity with the author's intentions and the work's structural features, artistic conventions, genre, etc. (see, e.g., Walton (1990), ch. 4; Van Leeuwen (2013), 228; Stock (2017), ch. 6). But this is not a crucial point for the proposed account of immersion. However the implicit to-be-imagined propositions are identified, what matters vis-à-vis immersion is, again, the extent to which the imaginer acquires beliefs about these propositions. To the extent that the imaginer thinks about which propositions are implicitly presented as fictional truths, and holds conscious, occurrent beliefs about them in the course of following the general rule that they are to be imagined, her immersion diminishes. To the extent 
that she gains familiarity with the factors that determine what the work implicitly sets down as fictionally true, and hence acquires fewer, or no, explicit beliefs about the implied fictional truths, her immersion increases.

Indeed, Liao's claim that immersed imaginers attend to the "happenings of the story world" rather than "the writing style, the plot structure, and other features about the book itself" (Liao, unpublished, 7) is partly correct. Insofar as the reader imagines the happenings of the story's world, she attends to them even if she is not immersed in her imaginings. But it is true that if, in addition to imagining, the reader explicitly thinks about the work's structure, style, etc., she is less immersed in imagining. On the proposed account of imaginative immersion, this diminished immersion ensues because in order to follow the general rule or norm of imagining (i.e., to imagine that which is presented as fictionally true), an imaginer who lacks familiarity with the factors that determine which implicit propositions are apparently fictionally true must actively acquire beliefs about them.

The distinction between doxastically-mediated imagining and non-doxastically-mediated imagining is relevant not only to works of fiction, but also to other sorts of guided imaginative projects. External guidance as to which propositions are fictional truths can, e.g., come from 'props,' as in the stumps-are-bears game: a banana can be a telephone, an actor can be Henry V, etc. The fictional truths generated by such props inform imaginings either mediately, via explicit beliefs that specific propositions are presented as fictional truths, or directly, without the mediation of such beliefs. An actor who plays Henry V, for instance, does not need to explicitly think about the specific fictional truths that are generated at each stage of the drama: he can imagine these propositions without doxastic awareness that they are fictional truths, in which case he will be more immersed in his imaginings. Those watching his performance may likewise 
imagine the said propositions either via beliefs about the fictional truths, or directly. As shown in $\S 4.1$, perceptual experience often plays a role in prompting doxastically-unmediated imagining. That an imaginer can perceive an object and immediately imagine the fictional truths it generates is particularly relevant to becoming immersed in visual works of fiction, e.g., plays, movies, and, on some views, pictures, sculptures, etc. ${ }^{11}$

A further variable on which the degree of immersion depends is the extent to which one's imaginings arise in response to one's own (explicit) intentions. ${ }^{12}$ Someone can intend to imagine, say, that she is walking through the jungle, a tiger starts to chase her, and she manages to escape. In such cases, the degree to which the imaginer is immersed is relatively low, or more precisely: lower than it would be were these imaginings to ensue spontaneously. As Walton argues (1990, 14-15), one who imagines unintentionally, finding herself presented with 'facts' of a fictional world, is generally more immersed in imagining than she would be had her imaginings arisen in response to intentions to imagine. On the account of immersion I am proposing, this is because intentions to imagine entail explicitly thinking about the fictional world: imagining by summoning up the 'to-be-imagined' propositions - i.e., those that one plans to invoke as the pertinent fictional truths — straightforwardly entails that the imaginings are doxastically-

${ }^{11}$ See Walton (1990), ch. 8; see also Chasid (2016).

${ }^{12}$ I am assuming, as is widely accepted, that imaginings can arise spontaneously, i.e., without intentions. Those who maintain that spontaneous imaginings rest on implicit intentions, or on what are sometimes called 'tacit' intentions (see, e.g., Boghossian 2008, 488), can construe the distinction in question as that between explicitly-intended imaginings, and implicitly- or tacitlyintended imaginings. 
mediated. ${ }^{13}$ In short, the extent to which imaginings ensue non-deliberately is another variable that determines an imaginer's degree of immersion. Spontaneous imaginings are indeed "more gripping" (Walton 1990, 15), because having fewer (or no) intentions-to-imagine means that the pertinent fictional truths are 'revealed' without doxastic mediation.

Yet another variable on which the degree of immersion depends is the imaginer's relation to the mental imagery that accompanies her imaginings. Mental images can arise in spontaneous imagining, in intended imagining, in imaginings that unfold in response to instructions, etc. ${ }^{14}$ In general, mental images convey to us what various things look like, sound like, etc. When called up in an imaginative project, they present certain propositions as fictional truths (i.e., propositions that are to be imagined), thereby inducing us to imagine these propositions. ${ }^{15}$

${ }^{13}$ As Setiya $(2018, \S 5)$ points out, it is widely accepted that intentions entail beliefs about what one intends to do. Yet even without this premise, having an explicit intention to imagine certain propositions entails having a mental representation of what one intends to imagine. The ensuing imaginings are thus mediated by occurrent, non-dispositional representations about that which is fictionally true, hence the low degree of immersion.

${ }^{14} \mathrm{My}$ argument is neutral regarding the controversial question of whether mental images necessarily arise in imaginative projects; see Walton (1990), 13; Kind (2001); (2016), 7; Van Leeuwen (2013), 222.

${ }^{15}$ The intuition that mental images are akin to perceptual experiences seems to be supported by psychological research: empirical findings show that the more vivid (i.e., clear, colorful, welldefined) mental images are, the more similar they are to perceptual experiences; see, e.g., Green and Donahue $(2009,244)$; Iachini $(2019,292)$. Moreover, the correlation between vividness of 
Vis-à-vis immersion, the crucial question is, again, whether our imaginings are mediated by explicit beliefs about the fictional scenarios depicted by mental imagery. Mental images can, in principle, present fictional scenarios, and direct us to imagine certain propositions, without mediation by beliefs; insofar as they do so, mental images can, in themselves, increase immersion. But they sometimes involve doxastic mediation. First, if mental images arise in response to an intention to imagine, the imaginer will be less immersed than she would be were the very same imaginings and images to arise spontaneously (unbidden, unintentionally), as explained above apropos imaginative projects that arise in response to intentions. ${ }^{16}$

Secondly, even when a mental image arises spontaneously, we sometimes imagine the fictional content it depicts via mediating beliefs about that content: we first acquire explicit beliefs about the propositions the image presents as fictionally true, then proceed to imagine those propositions. Such doxastic mediation diminishes immersion. In cases where the image is insufficiently vivid (see note 15), imagining the to-be-imagined propositions - the propositions that the image presents as fictionally true - may oblige us to acquire beliefs of the form 'this is what the fictional scenario looks like.' In such cases, since our imaginings proceed via doxastic

mental images and absorption in imaginings is also supported by empirical evidence (Donahue 2009; Iachini 2019). The proposed account of imaginative immersion explains this correlation: vivid images, in resembling perceptual experiences to a significant degree, require less awareness, on the part of the imaginer, of the manner in which they present the fictional world, and hence enable her to be more immersed in her imaginings.

16 There is empirical support for this claim: Iachini et al. (2019) found that control over mental images is not positively correlated with characteristic features of immersion. 
mediation, we are less immersed than we would be in cases where we can imagine what the image depicts without acquiring specific mediating beliefs. In short, mental images present a perception-like portrayal of the fictional world. To the extent that their content is imagined without the mediation of explicit beliefs about or explicit intentions as to that content, imaginative immersion is enhanced.

To recapitulate, given that immersion is gradational, not binary, the degree to which an imaginer is immersed in imagining depends on the degree to which her imaginings are mediated by beliefs. Propositions can be presented as fictional truths - and hence, as the content that is to be imagined - in various ways, for instance, through the use of props, through instructions to imagine various scenarios, patterns of inference, structural factors, mental images, etc.; with respect to each mode of presenting fictional truths, the rule or norm that the apparent fictional truths are to be imagined can be followed with varying degrees of directness, or more precisely, involves explicit mediating beliefs to varying degrees. To the extent that we imagine without acquiring such beliefs, we are more immersed in imagining.

\section{Attentiveness, Emotional Responses, Spoilers}

The proposed account assumes that 'immersion' does not always connote attentiveness. In certain contexts, specifically, that of imagining, being immersed in an activity is related to the normative dimension of that activity. In these contexts, one is deemed more immersed in the activity to the extent that one applies the rules that govern it without acquiring explicit beliefs about how the rules are to be applied to the particular instance at hand. Undeniably, being immersed in works of fiction, games of make-believe, daydreams, etc., differs from immersion in 
cultural or linguistic activities. Imaginings, unlike the latter activities, pertain to a fictional world: they are regulated by that which is presented, in the pertinent imaginative project, as fictionally true.

This similarity between imaginings and beliefs can create the impression that an immersed imaginer loses track of reality, takes the imagined propositions to be true, is unaware that she is imagining (Schellenberg 2013; cf. Liao and Doggett 2014). If imaginings (and their 'outputs': emotions, motivations, etc.) are governed directly by what is presented as true in the fictional world, it might seem as if an immersed imaginer, being in the grip of the fictional, is ignorant of real-world facts, unaware that she is imagining, etc. Yet this is not so, as the arguments mentioned in $\$ 2.1$ show. Immersed imaginers $d o$ have the general awareness that they are imagining, and can distinguish between reality and fiction. What they lack is real-time awareness of the details of how their imaginings comply with the rule or norm governing imagining in general, namely, that imaginers are to imagine that which is presented as fictionally true. This rule or norm becomes 'transparent,' just as grammatical rules or cultural norms become 'transparent' for those who are immersed in a language or culture.

Some aspects of immersion may indeed induce the imaginer to be particularly attentive to the fictional world, and thus less aware of her actual environment. One such aspect is the presence of mental images. Becoming immersed by way of imaginings accompanied by vivid mental images (discussed in $\S 4.2$ above) reduces the imaginer's perception of real-world facts. It is empirically established that perceptual experience disrupts mental imagery (see, e.g., CraverLemley and Reeves (1992); Vredeveldt et al. (2011)). Although imagining can continue even if perceptual stimuli disrupt mental imagery, this disruption increases the number of the imaginer's explicit beliefs about the apparent fictional truths (e.g., beliefs such as 'this is what the fictional 
creature looks like'), diminishing immersion. Accordingly, to the extent that an imaginer perceptually 'tunes out' her environment, she imagines the 'truths' presented by the mental images via fewer mediating beliefs, and her immersion increases.

Of course, intense attentiveness to an imaginative project generally lessens an imaginer's attention to real-world facts. For it is a commonplace that concentrating on one thing renders us less aware of other things. However, low awareness of real-world facts due to intense attentiveness to one's imaginative project does not straightforwardly distinguish immersed imaginers from non-immersed. Attentive to their respective imaginative projects in one way or another, both immersed and non-immersed imaginers may not notice that their coffee is getting cold, someone has entered the room, etc. What distinguishes an immersed imaginer from a nonimmersed imaginer is the extent to which they acquire beliefs about the to-be-imagined propositions. Whereas the immersed imaginer attends to the fictional content solely, or mainly, by imagining it, the non-immersed imaginer's attention is divided between acquiring explicit beliefs about the fictional content and imagining that content.

Considering the difference between a non-immersed imaginer and a non-imaginer can further clarify the relation between attentiveness and immersion. Emerging from a daydream, one is no longer immersed in it simply because one is no longer engaged in imagining. Finding a novel boring, and barely attentive to its fictional content, the reader hasn't lost her immersion in imagining that content while continuing to imagine it without immersion, but has simply stopped imagining that content. Similarly, a sudden thirst, hearing a door slam, etc., can bring imaginings to an end. The abrupt loss of attentiveness to fictional content is not ordinarily indicative of nonimmersion, but rather, indicates the cessation of imagining. Of course, an imaginer who decides to re-engage with a disrupted imaginative project will not become re-immersed immediately, 
since she must re-engage with the project by acquiring explicit beliefs, i.e., must recall the project's fictional content at the disruption point.

The proposed cognitive model of imaginative immersion also explains the imaginer's responses to her imaginings. As I argued in $§ 2.1$, immersion cannot be defined or explained in terms of an imaginer's responses to her imaginings, since responses (e.g., emotional, motivational, etc.) are not always relevant to imagined content: the imaginer can be immersed in imagining without responding in any specific way. Where responses are relevant, however, immersed imaginers seem to respond to imaginings differently than non-immersed imaginers do, for instance, by being more emotionally engaged in the fictional content (see, e.g., Green and Donahue 2009; Langland-Hassan 2020, ch. 9).

On the proposed account, such differences are not due to differences in the imagined content: immersed and non-immersed imaginers can imagine the same propositions. The fact that, despite imagining the same content, the immersed and the non-immersed imaginers respond to their imaginings differently, ensues from the general difference between an imaginer's emotional response to imagining a proposition, and her emotional response to believing that proposition to be fictionally true (see, e.g., Doggett and Egan 2012; Van Leeuwen 2020). Since beliefs about fictional truths play a role in the imaginer's overall system of beliefs and desires (and can therefore serve as reasons for real-world conduct), they tend to generate emotional responses that differ from those generated by imagining the fictional truths in question. For instance, imagining that a hero sacrifices himself might generate sorrow, regret, or admiration (or, for those who accept imaginative analogs of emotions: 'i-sorrow,' 'i-regret' etc.; see, e.g., Doggett and Egan 2012; Gendler and Liao 2019, §2.2), whereas the belief that it is fictionally true that the hero sacrifices himself might, as a belief about how the fictional events have 
unfolded, generate aesthetic pleasure. A belief that it is fictionally true that the hero's long journey will not end soon may annoy the reader, since she knows she must soon stop reading and get back to work, whereas the reader's imagining that the journey will not end soon might generate fear, frustration, etc.

On the proposed account, the fact that imaginings tend to generate emotional responses that differ from those generated by beliefs about the same fictional truths explains why an immersed imaginer is more emotionally engaged with the fictional content than a non-immersed imaginer is. Since in addition to imagining various propositions, a non-immersed imaginer also holds beliefs about these propositions' being fictional truths, his real-time emotional state is determined by those beliefs as well as by his imaginings. The real-time emotional state of an immersed imaginer, however, is determined solely by imaginings. Not having (real-time) beliefs about the fictional truths, the immersed imaginer responds emotionally to the imagined propositions, achieving greater emotional engagement with them than is attained by a nonimmersed imaginer, who is also responding emotionally to her explicit beliefs about the fictional truths.

The same sort of argument might apply in contexts where imaginings can engender motivations to act, e.g., pretending and games of make-believe. Since an immersed imaginer has fewer, or no, beliefs about the fictional truths, she seems to act solely on the strength of her imaginings, whereas a non-immersed imaginer seems to act on the strength of her beliefs about the fictional truths (i.e., about how she is supposed to act in the pretend world). However, since there is an ongoing debate over whether, and the extent to which, imaginings can directly 
motivate an imaginer to act, ${ }^{17}$ this putative difference between immersed and non-immersed imaginers should be discussed separately.

Spoilers are another phenomenon that the proposed cognitive model of imaginative immersion explains. Spoilers apprise us of a given work of fiction's truths and plot developments - especially the ending - before we have engaged with the work. Although they do not thwart imagining, they have an adverse effect on our engagement with the work. What accounts for this adverse effect? After all, beliefs about the fictional truths cannot spoil a reader's or viewer's engagement with a work of fiction directly. Rather, such beliefs affect our engagement with the fictional work in question indirectly, by influencing the way we imagine the fictional content.

Note that the phenomenon of spoilers confirms that imaginings are inherently rulegoverned. Were imaginings totally unconstrained, following instructions to imagine certain propositions while knowing what we are going to be asked to imagine later would not pose any problem. Advance knowledge of the fictional truths would not interfere with our imaginings were it not the case that they were supposed to unfold in a specific way-a way that can be influenced, and sometimes disrupted, by beliefs about what we will be asked to imagine at a later stage.

Imaginative regulation explains the spoiler phenomenon. Imaginings are regulated by that which a work of fiction presents, at each point in its unfolding, as fictionally true. When we know all the fictional truths beforehand, complying with the constraints on imagining while reading the work is disconcerting, and impels us to have recourse to explicit doxastic mediation.

\footnotetext{
${ }^{17}$ For an overview, see Ichino (2019).
} 
Spoilers do not thwart imagining, but they prevent us from becoming immersed in imagining. We can imagine what the work describes as true at each stage, but to do so, we must remain mindful of any differences between the set of fictional truths (which the spoiler has apprised us of), and what is currently being presented as fictionally true, set aside our knowledge of the former, and find the proper way to imagine only the latter.

Carrying out this task may be difficult. Consider an example. Suppose that, without having any exposure to a spoiler, the work we are reading initially describes A as benevolent, or B as dying. We respond by readily imagining that A is benevolent / B is dying, and also 'inflate' our project by imagining the likely consequences of A's benevolence / B's impending death. But if we know, from a spoiler, that it is fictionally true that A is malevolent, and that B eventually recovers, it is difficult to comply, as per the general rule or norm that regulates imagining, with the novel's prompts to imagine that A is benevolent / B is dying, and difficult to imagine the consequences of A's benevolence / B's prospective death. The difficulty ensues because reading the initial descriptions of A or B immediately elicits the beliefs about A and B acquired from the spoiler. We must therefore set these beliefs aside and focus on the propositions currently being presented as fictional truths: we must discern the truths that follow from the novel's description of $\mathrm{A}$ as benevolent / $\mathrm{B}$ as dying, without taking into consideration what we already know about A and B. Pinpointing which propositions are currently being presented as truths involves acquiring explicit beliefs about those propositions, hence our imaginings become doxasticallymediated, and our immersion is reduced. In general, a spoiler adversely affects our engagement with fiction because it imposes the burden of detecting the apparent fictional truths, thereby reducing our immersion. 
In sum, though spoilers do not thwart imagining, they diminish our ability to be immersed in imagining, as they make it difficult for imaginings to be governed directly by the apparent fictional truths. In so doing, they also affect our (real-time) emotional responses to the fictional content. As I explained, emotional responses to imaginings alone differ from emotional responses to imaginings that are accompanied by beliefs about the fictional truths, since beliefs about those 'truths' tend to generate different emotional responses than imaginings do. If we've been exposed to a spoiler, when we proceed to read the novel, our overall occurrent cognitive state incorporates both imaginings and beliefs (i.e., beliefs about the fictional truths). Moreover, thinking about what we are currently being asked to imagine, and distinguishing it from what we will be asked to imagine, renders our overall emotional state very different from the emotional response we would have were we to imagine only the propositions currently presented as fictional truths (i.e., had we not been exposed to the spoiler).

If, despite the spoiler, we succeed in setting aside our beliefs about the fictional truths, so that no such beliefs are prompted when we engage with the work in question, we can become immersed in imagining, and our engagement with the work will not be spoiled. For in general, to the extent that our imaginings are guided solely by the apparent fictional truths, we are immersed in the imaginative project, without any 'dilution' of the experience due to beliefs.

\section{Conclusion}

In many cases, immersion in an activity is not simply a matter of attentiveness, but ensues from the way in which the rules or norms applicable to that activity are followed. The more they are followed without explicit doxastic mediation, the greater the immersion. This is specifically true 
of imaginative immersion: to the extent that an imaginer follows the general rule or norm governing imagining (namely, that imaginers are to imagine the propositions presented as fictionally true) without acquiring explicit beliefs about which propositions are presented as fictional truths, she is more immersed in her imaginings.

Immersion is gradational, not all-or-nothing. Given that propositions can be presented as fictional truths in different ways, how immersed in her imaginings an imaginer becomes depends on several variables. With respect to each of them, to the extent that imaginings arise without mediating beliefs, immersion increases. The proposed cognitive model of imaginative immersion, I showed, explains various features associated with imagining, including attentiveness, emotional responses, and the adverse effect of spoilers.

The model also elucidates characteristics of imaginative immersion that come up in the empirical research on immersion. For instance, the sense of "flow" associated with being immersed (Green and Donahue 2009, 243) — presumably, effortless concentration on the imaginative project - is explained by the fact that immersed imaginers follow the rule or norm regulating imagining without reflecting on how it is to be followed. The correlation between immersion, lack of control over mental images, and vividness of mental images (see notes 15 and 16) may be explained by the thesis that the more spontaneous and vivid an image is, the less there is a need for mediating beliefs in order to imagine what it presents as fictionally true.

These and other features of imaginative immersion require further investigation. Specific features that call for explanation include the sense of being 'transported' into the fictional world (Green and Donahue 2009, 243), the feeling of 'presence' in the fictional world (Iachini et al. 2019, 294), and similar features associated with the imaginer's sense of being part of the fictional world. These feelings, I contend, can be explained by the thesis that just as beliefs are 
governed by truths, imaginings are governed by the (apparent) fictional truths. For it seems that in imagining, an immersed imaginer adopts the perspective of a believer toward the imagined content, perhaps taking herself to be a 'fictional believer.' ${ }^{18}$ This claim, however, merits a separate discussion.

* This research was supported by the Israel Science Foundation (grant No. 1544/20)

\section{References}

Audi, Robert (1994). "Dispositional beliefs and dispositions to believe," Noûs 28 (4):419-34.

Boghossian, Paul A. (2005). "Rules, Meaning and Intention - Discussion,” Philosophical Studies 124 (2):185-197.

Boghossian, Paul A. (2008). "Epistemic Rules,” Journal of Philosophy 105 (9):472-500.

${ }^{18}$ Kampa (2018) argues for a thesis in this vein, though his account endeavors to explain imaginative transportation, namely, cases where the imaginer imagines herself to be part of the fictional world, whereas immersed imaginers do not always imagine themselves to be part of the fictional world. The imaginer's presence in the fictional world can be explained by adducing Walton's distinction between the 'work world' and the 'game world' (Walton 2015, ch. 2, §5), but Walton's distinction only applies to engaging with works of fiction. Another account of the imaginer's supposed 'presence' in the fictional world is given in Chasid (forthcoming-a, §5), which addresses imagining in general, not just imaginative immersion. 
Chasid, Alon (2016). "Imaginatively-Colored Perception: Walton on Pictorial Experience," Southern Journal of Philosophy 54 (1): 27-47.

Chasid, Alon (2017). "Imaginative Content, Design-Assumptions and Immersion," Review of Philosophy and Psychology 8 (2): 259-272.

Chasid, Alon (2019). "Imagining in response to fiction: unpacking the infrastructure," Philosophical Explorations 23 (1):31-48.

Chasid, Alon (forthcoming-a). "Belief-Like Imagining and Correctness," American Philosophical Quarterly.

Chasid, Alon (forthcoming-b). "Not by Imaginings Alone: On How Imaginary Worlds are Established," Journal of the American Philosophical Association.

Craver-Lemley, C. and Reeves, A. (1992). "How Visual Imagery Interferes with Vision," Psychological Review 99 (4): 633-49.

Currie, Gregory (1998). "Pretence, Pretending, and Metarepresenting," Mind and Language 13 (1):35-55 .

Currie, Gregory and Ravenscroft, Ian (2002). Recreative Minds: Imagination in Philosophy and Psychology. Oxford: Oxford UP.

Doggett, Tyler and Egan, Andy (2012). "How We Feel About Terrible, Non-existent Mafiosi," Philosophy and Phenomenological Research 84 (2):277-306.

Frankish, Keith (2016). "Playing Double: Implicit Bias, Dual Levels, and Self Control," in M. Braunstein and J. Saul (eds.) Implicit Bias and Philosophy (vol. 1), Oxford: Oxford UP, pp. 23-46.

Ginsborg, Hannah (2011). "Primitive Normativity and Skepticism about Rules," Journal of Philosophy 108 (5):227-254. 
Glüer, Kathrin and Wikforss, Åsa (2020). "The Normativity of Meaning and Content”, The Stanford Encyclopedia of Philosophy, Edward N. Zalta (ed.), URL = <https://plato.stanford.edu/archives/fall2020/entries/meaning-normativity/>.

Green, M.C., and J.K. Donahue (2009). "Simulated Worlds: Transportation Into Narrative," in K.D. Markman, W.M.P. Klein, and J.A. Suhr (eds.), Handbook of Imagination and Mental Stimulation (New York: Psychology Press), pp. 241-254.

Harris, Paul L. (2000). The Work of the Imagination, Oxford: Blackwell.

Harris, Paul L., \& Kavanaugh, Robert D. (1993). Young Children's Understanding of Pretense. Monographs of the Society for Research in Child Development, 58(1): 1-107.

Horst, David (2019). "How Reasoning Aims at Truth," Noûs: early view: 1-28.

Iachini T., L. Maffei, M. Masullo, V. P. Senese, M. Rapuano, A. Pascale, F. Sorrentino, G. Ruggiero (2019). “The Experience of Virtual Reality,” Cognitive Processing 20(3):291-298. Ichino, Anna (2019). "Imagination and Belief in Action," Philosophia 47:1517-1534

Kampa, Samuel (2018). "Imaginative Transportation,” Australasian Journal of Philosophy 96 (4):683-696.

Kind, Amy (2001). "Putting the Image Back in Imagination," Philosophy and Phenomenological Research 62:85-109.

Kind, Amy (2013). "The Heterogeneity of the Imagination,” Erkenntnis 78 (1):141-159.

Kind, Amy (2016). "Introduction," in Amy Kind (ed.), Routledge Handbook of Philosophy of Imagination. New York: Routledge, 1-11.

Langland-Hassan, Peter (2020). Explaining Imagination. Oxford: Oxford UP. Liao, Shen-yi (unpublished ms.). "Immersion is Attention/Becoming Immersed." 
Liao, Shen-yi. and Doggett, Tyler (2014). “The Imagination Box,” Journal of Philosophy 111 (5): 259-275.

Liao, Shen-yi and Gendler, Tamar (2019). "Imagination," The Stanford Encyclopedia of Philosophy, Edward N. Zalta (ed.), URL = <https://plato.stanford.edu/archives/win2019/entries/imagination/>.

Lyons, Jack (2016). “Unconscious Evidence,” Philosophical Issues 26 (1):243-262.

Mandelbaum, Eric (2016). “Attitude, Inference, Association: On the Propositional Structure of Implicit Bias," Nô̂s 50 (3):629-658.

Nichols, Shaun (2006). "Introduction," in S. Nichols (ed.). The Architecture of the Imagination, Oxford: Oxford UP, pp. 1-16.

Nichols, Shaun and Stich, Stephen (2003). Mindreading: an Integrated Account of Pretence, Self-Awareness, and Understanding of Other Minds, Oxford: Oxford UP.

Pettit, Philip (1990). “The Reality of Rule-Following,” Mind 99 (393):1-21.

Schellenberg, Susanna (2013). "Belief and Desire in Imagination and Immersion." Journal of Philosophy 110 (9): 497-517.

Schlosser, Markus E. (2011). “The Metaphysics of Rule-Following,” Philosophical Studies 155 (3):345-369.

Schwitzgebel, Eric (2019). "Belief," The Stanford Encyclopedia of Philosophy, Edward N. Zalta (ed.), URL = <https://plato.stanford.edu/archives/fall2019/entries/belief/>. Setiya, Kieran (2018). "Intention,” The Stanford Encyclopedia of Philosophy, Edward N. Zalta (ed.), URL $=<$ https://plato.stanford.edu/archives/fall2018/entries/intention/>. Sinhababu, Neil (2016). "Imagination and Belief," in Amy Kind (ed.), The Routledge Handbook of Philosophy of Imagination. New York: Routledge, pp. 111-123. 
Skolnick Deena, and Bloom, Paul (2006). “The Intuitive Cosmology of Fictional Worlds,” in S.

Nichols (ed.), The Architecture of the Imagination: New Essays on Pretence, Possibility, and Fiction, Oxford: Oxford UP, pp. 73-86.

Stock, Kathleen (2017). Only Imagine: Fiction, Interpretation and Imagination. Oxford: Oxford UP.

Tuna, Emine Hande (2020). “Imaginative Resistance,” The Stanford Encyclopedia of Philosophy, Edward N. Zalta (ed.), URL = <https://plato.stanford.edu/archives/sum2020/entries/imaginative-resistance/>.

Van Leeuwen, Neil (2013). “The Meanings of 'Imagine’ Part I: Constructive Imagination,” Philosophy Compass 8 (3): 220-230.

Van Leeuwen, Neil (2020). “Imagining Stories: Attitudes and Operators,” Philosophical Studies:1-26.

Vredeveldt, A., Hitch, G.J. and Baddeley, A.D. (2011). "Eyeclosure Helps Memory by Reducing Cognitive Load and Enhancing Visualization," Memory and Cognition 39:1253-1263.

Walton, Kendall. L. (1990). Mimesis as Make-Believe. Cambridge MA: Harvard University Press.

Walton, Kendall. L. (2015). In Other Shoes: Music, Metaphor, Empathy, Existence. New York: Oxford University Press.

Weinberg, Jonathan and Meskin, Aaron (2006), "Puzzling Over the Imagination: Philosophical Problems, Architectural Solutions," in S. Nichols (ed.). The Architecture of the Imagination. Oxford: Oxford UP, pp. 175-202. 